\title{
М.А. Кузина
}

Аннотация. Двенадиатый ролан ("Кишот" (“Quichotte")) англоязычного писателя с индийскили корняли Салмана Рашди вошел в шорт-лист Букеровской прелии 2019 года. Как и многие другие романы лауреата Букеровской премии 1981 года, это художественное произведение наглядно доказывает необходимость соблюдения "приниипа Златовласки» в отношении включения в текст мультикультурного романа прецедентных илен, лингвокультурем и экзотической лексики. В целях достижения эбббективной комлуникации автор соблюдает определенный баланс, включая в текст экзотизлы (84 единицы) и слова с национально-культурныл колпонентом (32 единицы), а также более 100 преиедентных имен европейского и североамериканского истока. Первые две группы лексем выполняют фбункиию создания хронотопа и образа персонажей, третья группа слов способствует передачи авторской оценки персонажей и событий, созданию колпозииии художественного произведения, оказанию эстетического воздействия на читателя.

Ключевые слова: прецедентное имл, экзотическая лексика, лингвокультурема, мультикультурная литература, художественный дискурс.

\section{THE "GOLDILOCKS PRINCIPLE" IN S. RUSHDIE'S NOVEL "QUICHOTTE" (2019): The Ratio of the Precedent Names, Culturally-Loaded and Exotic Vocabulary}

\section{M.A. Kuzina}

Abstract. The twelfth novel ("Quichotte") by the English-speaking writer of Indian origin Salman Rushdie was short-listed for the Booker Prize in 2019. Like many other literary works by the Booker Prize winner of 1981, the ana- 
lyzed novel testifies to the necessity of following the Goldilocks Principle when resorting to precedent names, culturally-loaded words and loanwords from non-European languages. In order to effectively convey his ideas to the target reader the author juggles with exotic loanwords (84 lexemes), culturally-loaded words (52 lexemes) and over 100 allusions to European and North American texts, persons and phenomena. The exotic loanwords and the culturally-loaded words contribute to the depiction of the place, time and characters; however, the intertextual elements perform an evaluation function and an aesthetic function.

Keywords: allusions, exotic loanwords/loanwords form non-European language, culturally-loaded words, multicultural/cross-cultural literature, literary discourse.

3.

начимость и бурное развитие «мировой англоязычной литературы» во второй половине XX века отмечается многими исследователями современного английского языка: в частности, Д. Кристал называет этот феномен наиболее значимым в языковой истории: "The most notable development in the twentieth-century use of nonstandard English was the extension and flowering of the global literature... chiefly in those regions which became part of the British Commonwealth" [1, p. 502]. Наряду с британской и американской литературами мировая англоязычная литература включает «новые английские литературы» (“new literatures in English”), представленные произведениями писателей-мультилингвов из бывших колоний Британской империи. Для их обозначения также используются синонимичные термины «мультикультурная литература» ("multicultural literature”) и «кросс-культурная литература" ("cross-cultural literature”) [2, p. 386-389]. Таким образом, современный мультикультурный художественный дискурс - это и ответ колониальному роману ("imperial no- vels") Д. Дефро, Р. Киплинга, Дж. Конрада, Э. М. Форстера, Дж. Кери, и рассуждение о постколониальных ценностях нигерийцев, кенийцев, индийцев и граждан других государств, входящих в Содружество наций, и обращение к проблеме обратной колонизации.

В зарубежной лингвистике мультикультурная литература активно изучается: так, социальные сети Research Gate, Google Scholar, Academia.edu, созданные для сотрудничества ученых широкого спектра дисциплин, насчитывают более 100 исследований творчества Салмана Рашди (Salman Rushdie), лауреата Букеровской премии 1981 года за роман «Дети полуночи» ("Midnight's Children”) и дважды обладателя Букера Букеров - Лучшего Букера за 25 лет (1993) и Лучшего Букера за 40 лет (2008) [3].

В отечественной лингвистике идиостиль С. Рашди становится объектом изучения в двух диссертационных исследованиях на соискание степени доктора фрилологических наук (С.Р. Толкачев «Мультикультурный контекст современного ан- 
глийского романа» (2003), О.Г. Сидорова «Британский постколониальный роман последней трети XX века в контексте литературы Великобритании» (2005)) и в пяти диссертационных исследованиях на соискание степени кандидата филологических наук (А.В. Каличкина «Взаимодействие постмодернистских и постколониальных мотивов в творчестве С. Рушди» (2003), И.Ю. Облачко «Скрытые смыслы как компонент идиостиля С. Рушди и способы их представления» (2005), Н.3. Шамсутдинова «"Магический” реализм в современной британской литературе: Анжела Картер, Салман Рушди» (2008), И.Б. Елисеева «Дискурсивные особенности текста современной англоязычной пародии» (2011)), Е.А. Струкова «Образ творческой личности в произведениях англоязычных постколониальных писателей Дж.М. Кутзее и С. Рушди» (2016)). Некоторые аспекты творчества С. Рушди затрагиваются в диссертационных исследованиях на соискание степеней кандидатов исторических и политических наук, например: А. Аль-Биляль «Стереотипный образ ислама в англо-американской политологии и западных средствах массовой информации» (2006), Е.Ю. Чемякин “"Постколониальные исследования” как историко-культурный френомен второй половины XX века» (2012)). В этой связи справедливо отметить определенную практическую новизну предпринятого исследования, целью которого является определить необходимость соблюдения «принципа Златовласки» в отношении включения в текст мультикультурного романа прецедентных имен, лингвокультурем и экзотической лексики.
Биографию Салмана Рашди кратко можно представить в следующем виде. Писатель-мультикультуралист имеет индийские корни: он родился в 1947 году в Бомбее (в Британской Индии), с 1964 года он являлся британским верноподданным, а в 2016 году получил американское гражданство. Его часто характеризуют как «человека мира»: он прожил около сорока лет в Великобритании и около двадцати лет в США, он является почетным профрессором шести европейских и шести американских университетов, он является рыцарем Британской Империи «за служение литературе» (2007), президентом ПЕН-центра CШA (PEN American Centre, 20042006), членом Американской академии искусств и литературы (American Academy of Arts and Letters, 2008) и президентом Международного парламента писателей (International Parliament of Writers) [3].

С. Рашди, романист, эссеист, сценарист, начал литературную деятельность в 1975 году с романа “Grimus”, и уже второй роман "Midnight's Children" (1981) принес ему мировую славу. После "Shame" (1983), "The Satanic Verses" (1988), “The Moor's Last Sigh" (1995), "The Ground Under Her Feet" (1999), "Fury" (2001), "Shalimar the Clown" (2005), "The Enchantress of Florence" (2008), "Two Years Eight Months and Twenty-Eight Nights" (2015) последовали одиннадцатый роман “The Golden House", изданный на английском языке в сентябре 2017 года издательским домом Jonathan Саре и двенадцатый роман “Quichotte”, опубликованный в 2019 году издательством Random House [3].

Роман «Кишот» (“Quichotte”) вошел в шорт-лист Букеровской пре- 
мии 2019 года наряду с романами М. Этвуд “The Testaments”, Б. Эваристо "Girl, Woman, Other", Л. Эллманн "Ducks, Newburyport”, Ч. Обиoma "The Orchestra of Minorities", Э. Шафрак "10 Minutes 38 Seconds in This Strange World” [4]. Следует подчеркнуть, что четыре из шести представленных романов являются яркими образцами мультикультурной литературы за авторством писателей-мультилингвов с нигерийскими, турецкими и индийскими корнями. Сам автор трактует его как творческое переосмысление произведения «Хитроумный идальго Дон Кихот Ламанчский» (в 2-х т.: 1605, 1615) М. де Сервантеса, в котором немолодой коммивояжер пересекает всю Америку вслед за популярной медийной персоной, этнической индианкой, обличая и критикуя пороки и слабости современного американского общества: "He talked about wanting to take on the destructive, mindnumbing junk culture of his time just as Cervantes had gone to war with the junk culture of his own age" [5, p. 289].

Термины «принцип Златовласки» (правило держаться золотой середины и не впадать в крайности) и «эфрфект Златовласки» (результат соблюдения правила «золотой середины», разумного подхода к использованию неких ресурсов) используются в самых разных сфрерах: в әкономике, медицине, астробиологии, математике, статистике, психологии и лингвистике, причем в рамках лингвистики он интерпретируется как основное условие эфрективной коммуникации: "In communication, the Goldilocks principle describes the amount, type, and detail of communication necessary in a system to maximize effec- tiveness while minimizing redundancy and excessive scope on the "too much" side and avoiding incomplete or inaccurate communication on the "too little' side" [6].

Романы С. Рашди традиционно изобилуют экзотической лексикой, то есть словами иноязычного происхождения, обозначающими реалии языка-донора и выполняющими фрункцию создания инонациональной речевой среды. Для романов о жизни индийцев в колониальной Индии и в постколониальной Индии, а также о жизни индийских диаспор в Великобритании и США характерно использование заимствований из языков Южной Азии. Этот зонтичный термин включает все лексемы, которые можно возвести к тому или иному слово-прототипу в санскрите (например, ashram, kar$m a)$, в хинди (например, bangle, mahout), в урду (begum, hookah) и еще в 13 языках данного региона (например, от этимонов в тамильском языке ведут свое происхождение лексемы catamaran, pariah, patchouli) [2, p. 386-389]. В рамках тематической классификации экзотическая лексика обозначает географические, этнографические и общественно-политические реалии родины автора, которые могут быть незнакомы целевому англоязычному читателю.

Основными стратегиями введения незнакомой для целевого читателя лексики являются следующие приемы:

1) экзотизмы включаются в текст романа без графического выделения, без опоры на установившиеся синтагматические или парадигматические связи, например: "Miss Salma offered him samosas, gulab jamun, 
and dirty martinis (up, with olives) and listened with great, wide-eyed seriousness" [5, p. 42];

2) экзотизмы вводятся в текст только с опорой на их сочетаемостные возможности, например: "Не was not wearing a kurta-pajama, however, he was dressed like a good allAmerican boy, in a checked lumberjack shirt and denim jeans with turnups" [там же, p. 18];

3) экзотизмы включаются в текст в сопровождении гиперонима, синонима или антонима, например: "Sancho instantly recognizes that something impossible has happened: that this stranger is the perfect woman for him, the girl of his dreams, and fate karma kismet has brought him here to meet his only true love" [Ibid, p. 148];

4) экзотизмы включаются в текст в сопровождении однословного перевода или подробного комментария, например: "Zevar meant "ornamentation" in Urdu and Zayvar was the Anglophile patriarch's Englishing of the word" [Ibid, p. 31]. Автор выбирает стратегию ввода экзотизмов в современный текст на английском языке, принимая во внимание регистрацию заимствования в словарях языка-реципиента (или степень известности носителям языка-реципиента), семантику заимствования (или принадлежность к той или иной тематической группе), знакомство героев романа с описываемым явлением, важность понимания именно этого слова в контексте всего художественного произведения.

Лингвокультуремы, то есть единицы описания взаимосвязи языка и культуры, выделяемые с целью использования их в лингвострановедческой методике; они включают в себя сегменты не только языка (языкового значения), но и культуры (внеязыкового культурного смысла) и репрезентируются соответствующим знаком [7, с. 21, 44]. Лексемы с национально-культурной справкой в составе лексического значения получили и другие терминологические обозначения: безэквивалентная лексика (Е.М. Верещагин, В.Г. Костомаров, А.С. Мамонтов), реалии (Г.Д. Томахин), слова с национальнокультурным компонентом значения (Л.В. Малаховский, А.С. Мамонтов, Л.Т. Микулина), слова с культурноисторическим компонентом значения (В.В. Ощепкова). В рамках настоящего исследования под лингвокультуремой понимается обозначение реалии страны языка-донора при помощи средств языка-реципиента. Одной из ключевых лингвокультурем является "Partition", или процесс разделения бывшей британской колонии Британская Индия ("the British Raj") на независимые государства, что привело к массовым кровопролитным столкновениям и миграциям населения: “... and in the other country, a man was lynched by sacred-cow fanatics for the crime of having what they thought was beef in his kitchen, and an eight-year-old girl from a Muslim family was raped and killed in a Hindu temple to teach the Muslim population a lesson" [5, p. 54].

Неотьемлемой чертой мультикультурного романа стало включение в него значительного числа прецедентных имен, причем по большей части они соотносятся с культурноисторическим опытом метрополии, а не с культурно-историческим наследием бывшей колонии. Так, роман «Кишот» содержит около 100 контек- 
стов употребления прецедентных имен европейского и североамериканского истока; они относятся к следующим сфрерам-источникам:

1) Библия: "It was as if, Sancho thought, white lady's pointing finger had put the mark of Cain on them both, and now wherever they went there would be suspicion and hostility" [5, p. 141];

2) античная мифрология и произведения античных авторов: “O my warrior Sancho sent by Perseus to help me slay my Medusas and win my Salma's heart, here you are at last" [Ibid, p. 19];

3) народные и авторские сказки, народные баллады и легенды: "She stayed calm, held it together, just about, and called Anderson Thayer. Rumpelstiltskin, I need you. He came over and she kissed him, once, properly. I need you to fix this, she said. Don't tell me how, just fix it so I stays fixed"; "She took part in amfAR fundraisers and emceed the Robin Hood gala" [Ibid, p. 120];

4) короткие рассказы и романы: "Without killing there was no life. He knew that other writers could make masterpieces out of accounts of tea parties (e.g., the Mad Hatter's) or dinner parties (e.g., Mrs. Dalloway's) or, if you were Leopold Bloom, out of a day spent walking around a city while your wife was being unfaithful to you back home, but Brother had always needed blood" [Ibid, p. 280];

5) комиксы и графические романы: "Yes, he had forgotten them, placing them in a lead-lined casket of forgetting far beneath the bed of the remembering ocean within him, an unmarked sarcophagus impenetrable even by the X-ray vision of a Super- man, and along with them he had buried the man he had been then, and the things he had done, the failures, the failures, the failures" [Ibid, p. 16];

6) художественные и мультипликационные фрильмы Европы и Северной Америки: “The point of telling you this, sir, is that we, that is to say the appropriate agencies, wished to enlist Blind Joe in our battle against hacking, using the 'set a thief to catch a thief'. Like Cary Grant in the old Hitchhock movie" [Ibid, p. 221].

Особенностью идиостиля С. Рашди является построение цепочек из избыточного числа прецедентных имен; в тексте анализируемого романа их встречается не менее десяти, например: "My silly little Sancho, my big tall Sancho, my son, my sidekick, my squire! Hutch to my Strasky, Spock to my Kirk, Scully to my Mulder, BJ to my Hawkeye, Robin to my Batman! Peele to my Key, Stimpy to my Ren, Niles to my Frazier, Arya to my Hound, Peggy to my Don, Jesse to my Wallet, Tubbs to my Crockett, I love you!" [Ibid, p. 19]. В приведенном примере задействованы 24 прецедентных имени, в частности: имена и фрамилии героев детективных, приключенческих, франтастических фильмов и телесериалов “Старски и Хатч» (2004), «Звездный путь» (1965-1969), «Секретные материалы» (1993-2018) «Военно-полевой госпиталь» (19701983), «Бэтмен и Робин» (1997), «Кет и Пил» (2012-2015), «Фрейзер» (1993-2004), «Игра престолов» (20112019), «Безумцы» (2007-2015), «Во все тяжкие» (2008-2013), «Полиция Майами: Отдел нравов» (1984-1990). Справедливо отметить, что подобное построение текста предстает как зона коммуникативного напряже- 
ния: избыток не поддающихся декодированию прецедентных имен создает определенные сложности для целевого читателя и нарушает стабильность лексической системы языка [8, с. 152].

Еще одна черта идиостиля С. Рашди - многократное обращение к одному и тому же прецедентному имени в рамках одного художественного произведения. Так, к числу излюбленных сказочных антропонимов справедливо отнести "Rumpelstiltskin", "Dorothy", "Wicked Witch of the West", "Wizard of Oz", "Pinocchio": "...he felt himself becoming emotionally involved with many of the inhabitants of that other, brighter world, membership in which he thought of as a latter-day Dorothy contemplating a permanent move to Oz", "Tornadoes in the Midwest? Yeah, they're big, but tornadoes have been out there forever, even before Dorothy got spirited away to $\mathrm{Oz} "[5$, p. 4, 331].

Также следует отметить преобладание прецедентных имен со сферой-источником «Художественные и мультипликационные фрильмы Европы и Северной Америки» над всеми другими группами, причем наименее представленными оказываются библейские аллюзии (их только три: "Cain", "David and Goliath" и "Garden of Eden"). Прецедентные имена, восходящие к кинематографуу, часто вводятся в текст романа при помощи клине «like + имя актера/персонажа фрильма" и "имя актеpa/персонажа фрильма('s) + название одежды, части тела, характеристик поведения, черт характера» (причем в последней модели часто задействуются синтмаксические композиты и бленды): “He's afraid she'll slam her door in his face - No, that's the past, like Nastassja Kinski in one version of the Paris, Texas screenplay", "He closed his eyes and walked backwards across continents and years, twirling his cane like Raj Kapoor's imitationChaplin-tramp, only in reverse" [9, c. $56 ; 5$, p. 200, 30].

Таким образом, выявленный баланс между лингвокультуремами и заимствованиями из неевропейских языков (обе группы обозначают реалии бывших британских колоний) и широким спектром прецедентных имен (они апеллируют к фоновым знаниям носителей языка-реципиента) может быть интерпретирован с разных точек зрения. Во-первых, в зарубежном литературоведении данная особенность идиостиля писателеймультикультуралистов объясняется необходимостью успешного маркетинга как на их родине, так и за ее пределами, в особенности в Европе и США, Канаде [6, р. 198-199]. Для реализации оценочно-характеризующей и эстетической функций прецедентных имен они должны соотноситься с фроновыми знаниями и культурно-языковыми компетенциями целевого читателя. Во-вторых, отечественные исследователи мультикультурной литературы на английском языке объясняют интертекстуальные связи между европейскими (а также североамериканскими) и «экзотическими» литературными традициями как неотъемлемую часть гибридного мультикультурного пространства [10, с. 193]. Другими словами, поликодовость и апелляция к литературным источникам являются ведушими средствами концептуализации, категоризации и оценивания действительности, а также персонализации дискурса [11, с. 21]. В-третьих, 
ряд критиков считают число прецедентных имен в романах С. Рашди избыточным, что свидетельствует не о жизненном опыте, эрудиции, речевом мастерстве автора, а о «творческой лени» писателя, который жалуется на "the destructive, mind-numbing junk culture of his time": "It's spattered with Wiki-like chunklets of history (on the $18^{\text {th }}$-century black writer Ignatius Sancho, on early $20^{\text {th }}$-century Indian immigration to America) and semicomic riffs (on the difference between field hockey, on how douglas Adam's death after visiting a California gym proves that exercise is overrated). <...> This is lazy writing for lazy readers, eyeball-grabbing anti-prose for distracted device-users" [12]. В-четвертых, исследователи творчества С. Рашди объясняют наблюдаемый баланс лексических единиц как уважение к целевому читателю, для которого некоторые реалии колоний объясняются через обращение к фроновым знаниям жителей метрополии.

\section{СПИСОК ИСТОЧНИКОВ И ЛИТЕРАТУРЫ}

1. Crystal, D. The Stories of English. Pearson: Penguin Books, 2005. 584 p.

2. Durkin, Ph. Borrowed Words: A History of Loanwords in English. Oxford: Oxford University Press, 2014. $491 \mathrm{p}$.

3. The Official Site of Salman Rushdie. URL: https:www.salmanrushdie.com/ (дата обращения: 20.01.2020).

4. The British Broadcasting Corporation. URL: https://www.bbc.com/ (дата обращения: 20.01.2020).

5. Rushdie, S. Quichotte. New York: Random House, 2019. 390 p.

6. Barber, C., Sporton, K. Vivid Learning. URL: https://vividmethod.com/goldilocks-communicationjust-the-right-amount-of-information/ (дата обращения: 20.01.2020).

7. Воробьев, В.В. Лингвокультурология: (теория и методы). М.: Изд-во Росс. ун-та дружбы народов, 1997. $331 \mathrm{c}$.

8. Земская E.A. и др. К построению типологии коммуникативных неудач (на материале естественного русского диалога) // Русский язык в его функционировании: коммуникативнопрагматический аспект. М., 1993. 224 с.

9. Лаврова, Н.А. Основы языкознания: учебное пособие. М.: МПГУ, 2019. 252 с.

10. Толкачев, С.П. Гибридная образность в русской и английской постколониальной литературе // Филология и культура. 2017. № 2. С. 193-200.

11. Никулина, E.A. Современные английские фразеологизмы в поликодовом пространстве // III Международная научно-практическая конференция «Лингвистика, лингводидактика, лингвокультурология: актуальные вопросы и перспективы развития», Минск, 2019: материалы. Минск: Белорусский государственный университет, 2019. С. 21-24.

12. Sandhu, S. Quichotte by Salman Rushdie - Longlisted for the Booker. URL: https://www. theguardian.com/ (дата обращения: 20.01.2020).

\section{REFERENGES}

1. Barber C., Sporton K. Vivid Learning, available at: https://vividmethod.com/goldilocks-communi cation-just-the-right-amount-of-information/ (accessed: 20.01.2020).

2. Crystal D. The Stories of English. Pearson, Penguin Books, 2005, 584 p. 
3. Durkin Ph. Borrowed Words: A History of Loanwords in English. Oxford, Oxford University Press, 2014, $491 \mathrm{p}$.

4. Lavrova N.A. Osnovy jazykoznanija: uchebnoe posobie. Moscow, 2019, 252 p. (in Russian)

5. Nikulina, E.A. "Sovremennye anglijskie frazeologizmy v polikodovom prostranstve", in: III Mezhdunarodnaja nauchno-prakticheskaja konferencija "Lingvistika, lingvodidaktika, lingvokulturologija: aktualnye voprosy i perspektivy razvitija", Minsk, 2019: materialy. Minsk, Belorusskij gosudarstvennyj universitet, 2019, pp. 21-24. (in Russian)

6. Rushdie S. Quichotte. New York, Random House, 2019. 390 p.

7. Sandhu S. Quichotte by Salman Rushdie - Longlisted for the Booker, available at: https://www. theguardian.com/ (accessed: 20.01.2020).

8. The British Broadcasting Corporation, available at: https://www.bbc.com/ (accessed: 20.01.2020).

9. The Official Site of Salman Rushdie, available at: https:www.salmanrushdie.com/ (accessed: 20.01.2020).

10. Tolkachjov S.P. Gibridnaja obraznost v russkoj i anglijskoj postkolonialnoj literature, Filologija $i$ kultura, 2017, No. 2, pp. 193-200. (in Russian)

11. Vorobev V. V. Lingvokulturologija: (teorija i metody). Moscow, 1997, 331 p. (in Russian)

12. Zemskaja E.A. "K postroeniju tipologii kommunikativnyh neudach (na materiale estestvennogo russkogo dialoga)", in: Russkij jazyk v ego funkcionirovanii: kommunikativno-pragmaticheskij aspekt. Moscow, 1993, 224 p. (in Russian)

Кузина Марина Анатольевна, кандидат филологических наук, доцент, кафедра фонетики и лексики английского языка, Институт иностранных языков, Московский педагогический государственный университет, kouzina-marina@yandex.ru

Kuzina M.A., PhD in Philology, Associate Professor, Department of Phonetics and Lexicology of English Language, Faculty of Foreign Languages, Moscow Pedagogical State University, kouzinamarina@yandex.ru 